Gerald J. Holmes

North Carolina State University, Raleigh

Edward A. Brown

University of Georgia, Athens

Gail Ruhl

Purdue University, West Lafayette, IN

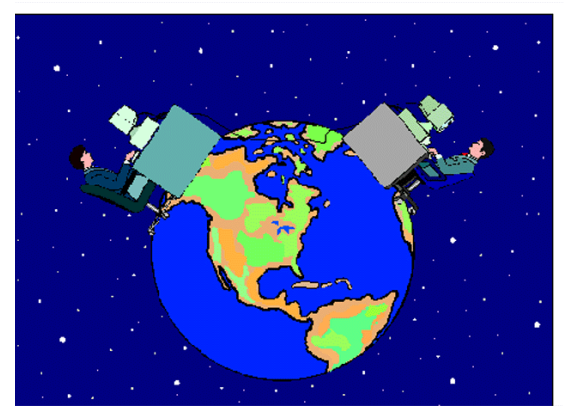

What's A Pieture Worth?

The Use of Modern Telecommunicetions in Diagnosing Plant Diseases

Plant disease diagnosis is an art as well as a science (8). The diagnostic process (i.e., the recognition of symptoms and signs) is inherently visual and requires intuitive judgment as well as the use of scientific methods. Photographic images of plant disease symptoms and signs are used extensively to enhance descriptions of plant disease and are invaluable in research, teaching, extension, and diagnostics. Modern telecommunications systems permit individuals to share high-resolution digital images among multiple locations within seconds. Plant pathologists can thus incorporate these digital imaging and digital image transfer tools into the process of plant disease diagnosis. As with the introduction of most new tools, techniques, or changes in protocol, there is controversy about how this tool should be used $(5,12,13,16-18,20,21)$.

The objective of this paper is to discuss the benefits, risks, and limitations associated with digitally assisted diagnosis (DAD) of plant diseases as well as the current status of this practice in the United States. Case scenarios included in this paper provide evidence that the transfer of high-quality digital images has been a successful tool in assisting long-distance consultation and the accurate diagnosis of plant problems. Examples of inappropriate uses of image transfer are also discussed.

\section{History and Current Status}

Images are important descriptive tools and have been with us since prehistoric

Dr. Holmes address is: North Carolina State University, Raleigh 27695

E-mail: gerald-holmes@ncsu.edu

Publication no. D-2000-1002-01F

(C) 2000 The American Phytopathological Society times. Since the advent of photography in the mid-1800s, photographic images have been critical in conveying information that was difficult to describe with words. Now that photographs can be digitized and sent around the world in seconds, they are being used for new purposes, such as telemedicine and DAD.

Telemedicine. Telemedicine is the delivery of health care and sharing of medical knowledge over a distance using telecommunications systems (22). The practice is analogous to DAD and offers insight into its applications and limitations. Telemedicine began in the 1960s $(1,2)$ and exploded in the 1990 s with the development of medical devices that capture images and other data in digital form, and with the development and installation of highspeed, high-bandwidth telecommunications systems worldwide. Today, nearly all medical-related facilities in the United States have implemented some form of telemedicine. Clinical applications are found now in virtually every specialty (e.g., radiology, cardiology, dermatology, psychiatry, emergency medicine, home health care, pathology, and oncology). One of the most common uses of telemedicine is in dermatology, which relies heavily on visual examination (7). Prisons and jails use telemedicine to avoid transferring prisoners to extramural medical facilities. The military uses telemedicine for treating front-line casualties. In fact, the military is currently one of the largest users of video consultation and has satellite connections to more than 70 remote sites (4). Literature about telemedicine can be found at the Telemedicine Bibliographic Database at http://tie.telemed.org/Bibliographic.asp.

Despite the rapid development of telemedicine, relatively few patients are receiving care through this medium. Factors cited as barriers to the implementation of telemedicine include liability concerns, physician licensing across state lines, absence of minimal standards, lack of reimbursement for services, and provider resistance to new technology (7).

Use of DAD in the agricultural sciences began in the early 1990s when the personal computer became capable of transmitting images. In 1999, two abstracts were published on the use of DAD $(3,11)$. Several universities had formalized programs for handling these images and training programs to aid those submitting digital samples. While several agricultural disciplines are now using DAD—entomology for insect identification, weed science for weed identification, and botany for poisonous plant identification-this practice is most widely used in plant pathology.

The University of Georgia pioneered the development of a statewide, web-based delivery system for DAD. In 1997, after 3 years of development, the University obtained private funding to implement a statewide agricultural diagnostics program, which they named Distance Diagnostics through Digital Imaging (DDDI). The project has equipped county extension offices with digital imaging stations in 94 of 159 counties. Stations include a computer, digital camera, dissecting and compound microscopes with digital camera attachments (Fig. 1A), and a set of 26 American Phytopathological Society disease compendia and other reference books. Digital imaging stations were also added at research stations in Athens, Tifton, and Griffin, for a total of 97 imaging stations. All counties have digital cameras and access to the DDDI system. The initial cost per imaging station was $\$ 10,000$, but sites are now deployed for approximately $\$ 6,000$ each. 
Survey results. Based on a May 2000 survey of university-related plant disease clinics in the United States, 46 of 50 respondents had received digital images for consultation (G. Ruhl, unpublished data). Eleven states reported the establishment of one or more formalized digital diagnostics sites strategically placed within their state and equipped with microscopes, digital cameras, and computers for the capture and transfer of digital images to diagnosticians and specialists for diagnostic consultation (Table 1). Five of these 11 states also funded the distribution of digital cameras to extension personnel at additional sites. Seven of these 11 states use web-based delivery systems, and four currently rely on e-mail. Four states provided only digital cameras to specified extension personnel. Oklahoma and Wyoming provided digital cameras and flatbed scanners to their test sites, and Wyoming also provided color printers (Table 1). Four additional states reported plans to implement formalized digital diagnostics systems in the near future. Sources of funding for the acquisition of digital cameras, computers, and other equipment necessary to establish formalized, statewide digital diagnostics systems included private gifts, in-house extension dollars, technology and distance education grants, and one master gardener association. Several states mentioned budget constraints as the primary reason for not incorporating digital images into their diagnostic procedure; other states reported philosophical objections. One state reported that they do not issue written diagnostic reports when only a digital sample is submitted, stating "digitals are for opinions and all digital images must be followed up with actual samples for a written report to be sent."

The number of digital images sent directly to diagnostic clinics or commodity specialists varies significantly among states. In 1999, Georgia and Tennessee received approximately 700 and 450 digital samples, respectively. Thirteen other university clinics received between 75 and 250 digital samples. The remaining 31 responding clinics received 1 to 25 digital images. Some states $\log$ in digital images in the same manner as a live sample; other states record digital images as e-mail entries and e-mail responses. Most states request follow-up, live samples for verification of diagnoses. Only three states handle digital images as they do live samples-they are logged in and assessed the standard fee for diagnosis. Follow-up samples are universally requested when poor-quality or nondescript digital images are submitted.

Because many of the systems are only accessible to the general public through extension delivery systems, county extension personnel are the primary group submitting digital images. Home gardeners and commercial growers are the second and third largest groups submitting digital images, respectively. The majority of digital images sent to universities for diagnosis are sent directly to the diagnostic clinics or labs and are viewed by diagnosticians. In some systems, the submitting client specifies a commodity group on a web-based form, and the digital images are sent directly to the commodity specialist.

Most diagnostic clinics archive good digital images. The Plant Disease and Insect Clinic at North Carolina State University has been receiving and archiving images since 1995. The sentiment expressed by numerous respondents was that good digital images of plant problems are most helpful when requesting diagnostic help from fellow diagnosticians and plant pathologists. One response mentioned the use of a library of digital plant disease images as a resource tool for commercial growers. Images of diseases and their causal agents are provided on a website, so growers in remote sites can access the images and compare them with what they are observing. It was suggested that this places the burden of extensive initial examination at the remote site rather than at the clinic, which is already working at full capacity.

While it is difficult to assess DAD programs in plant disease clinics outside the United States, based on international requests for information about $\mathrm{DAD}$, it is reasonable to assume that similar activities are occurring worldwide.
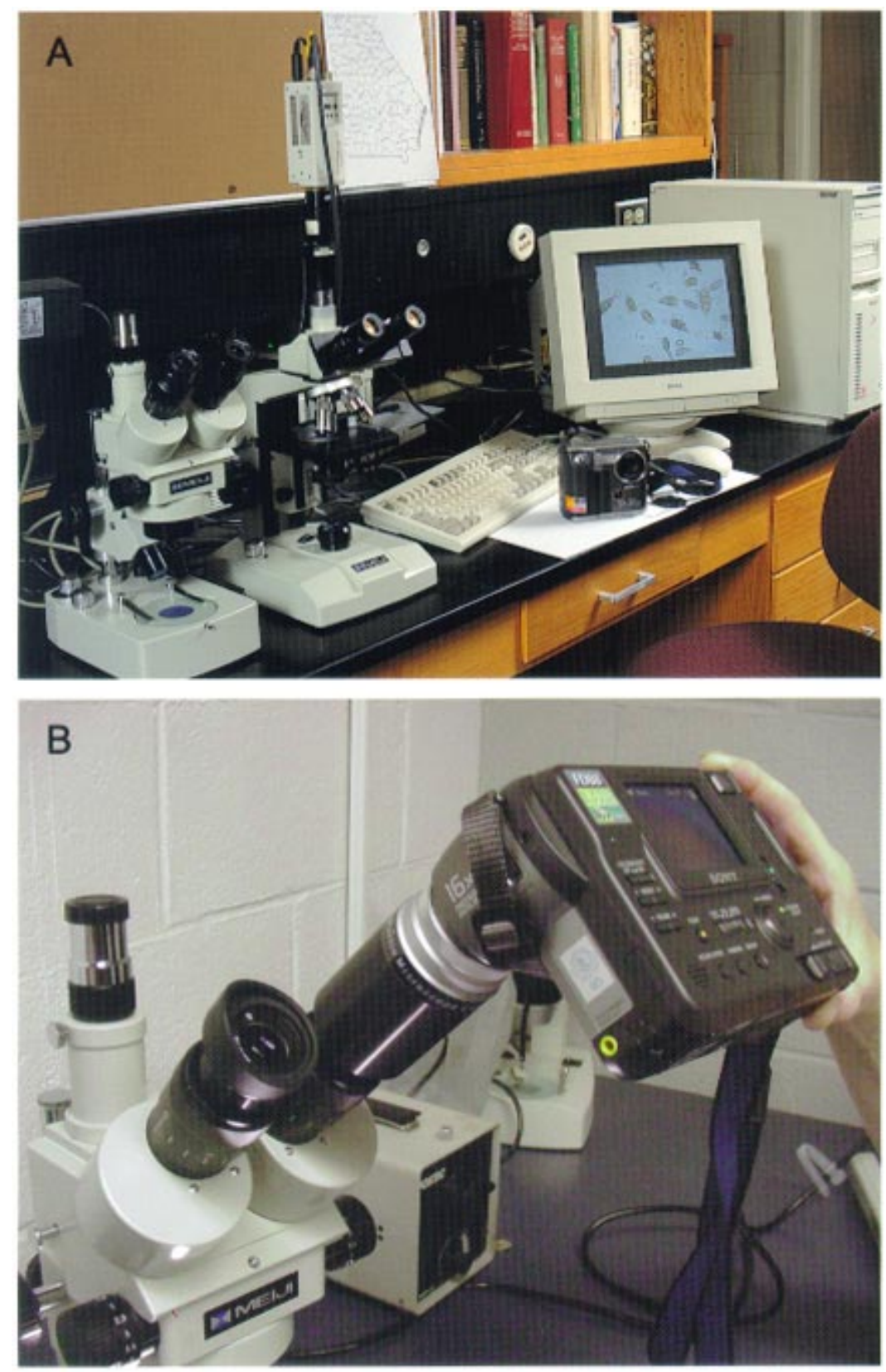

Fig. 1. Typical digital imaging station at the University of Georgia. Includes digital camera, dissecting and compound microscopes with video camera attachment, and personal computer with video capture board (A) (courtesy University of Georgia). Microscope ocular adapter (Martin Microscope Co., Easley, SC) for digital camera (Sony Electronics, Carson, CA) is an inexpensive way to acquire images of microscopic features (B) (courtesy G. Ruhl). 
Industry is also using DAD for their own purposes. Pioneer Hi-Bred International, Inc. (Des Moines, IA), which has worldwide crop-breeding operations, developed a DAD network in the mid-1990s. The network consists of 25 diagnostic imaging labs, half of which are located outside the United States. Each lab has a dissecting microscope, a compound microscope, a video camera (used as stand-alone or attached to a microscope), and a personal computer (with video capture board) valued at approximately $\$ 15,000$ (J. Berry, personal communication).
Griffin L.L.C. (Valdosta, GA) sells pest control products in 87 countries. Griffin has equipped each of its regional research and development representatives with a digital camera. The camera is used to document crop loss in research and evaluation plots and to facilitate communication among staff throughout the United States and the headquarters in Valdosta (J. Bone, personal communication).

Many other companies may be using DAD. However, no systematic attempt was made to survey the agricultural industry for their use of, or views on, DAD.

Table 1. May 2000 survey results of university-related plant disease clinics in the United States

\begin{tabular}{|c|c|c|c|c|}
\hline State & $\begin{array}{l}\text { Off-campus sites } \\
\text { with microscopes }\end{array}$ & $\begin{array}{l}\text { Off-campus sites } \\
\text { with cameras }^{b}\end{array}$ & Initial year & $\begin{array}{l}\text { Delivery } \\
\text { system }\end{array}$ \\
\hline Alabama & 7 & & 2000 & Web-based \\
\hline Connecticut $^{\mathrm{c}}$ & $2-3$ & & Near future & E-mail \\
\hline Florida (Quincy) & $10 ; 13^{\mathrm{d}}$ & & 1999 & Web-based \\
\hline Georgia & 97 & $61^{\mathrm{e}}$ & 1998 & Web-based \\
\hline Illinois & $16 ; 95^{\mathrm{d}}$ & 6 & 1999 & Web-based \\
\hline Indiana & 15 & & 2000 & Web-based ${ }^{f}$ \\
\hline Iowa & & 15 & 1998 & E-mail \\
\hline Louisiana & 10 & 54 & 1999 & Web-based \\
\hline Missouri & & 100 & 1999 & Web-based \\
\hline Nebraska & & 10 & 1998 & E-mail \\
\hline New York (Ithaca) & 1 & & Near future & E-mail \\
\hline North Carolina & $1^{\mathrm{g}}$ & $25^{\mathrm{e}}$ & 1996-1999 & E-mail \\
\hline North Dakota & 1 & 8 & 1998 & E-mail \\
\hline Oklahoma & 0 & 10 & 1999 & Web-based \\
\hline Oregon & 1 & & 2000 & E-mail \\
\hline South Carolina & 10 & & 1999 & Web-based \\
\hline South Dakota & & 27 & 1998 & E-mail \\
\hline Tennessee & 16 & & 1999 & Web-based \\
\hline Texas & 10 & 30 & Near future & Web-based \\
\hline Virginia & & $4-5$ & Near future & Web-based \\
\hline Wyoming & & $5^{\mathrm{h}}$ & 1998 & Web-based ${ }^{\mathrm{i}}$ \\
\hline
\end{tabular}

${ }^{a}$ Sites equipped with dissecting microscopes (some sites equipped with compound microscopes), digital or video cameras with microscope adapter and computer; sites located at county extension offices, regional centers, or other extension facilities.

b Numbers are digital cameras provided by "on-campus" dollars; digital cameras secured by other means are not listed; thus, actual number of sites with cameras exceeds number reported.

${ }^{c}$ Funded by the Connecticut Master Gardener Association.

${ }^{\mathrm{d}}$ Expansion of sites in 2000.

e Cameras provided in 1999.

${ }^{\mathrm{f}}$ Development of web-based submission system in progress.

$\mathrm{g}$ This site was set up independently by Extension Agent T. Dyson.

${ }^{\text {h }}$ Flatbed scanners and color printers were also provided.

i Although a web-based system was created, it has never been used by clientele; e-mail is the delivery system of choice.

Table 2. List of websites describing digitally assisted diagnostics (DAD) programs, webbased submission systems, and philosophies on DAD

\begin{tabular}{ll}
\hline Site description & Uniform resource locator (http://) \\
\hline University of Georgia: Distance Diagnostics & www.dddi.org \\
Through Digital Imaging (DDDI) & \\
University of Florida: Distance Diagnostic and & ddis.ifas.ufl.edu/ \\
Identification System (DDIS) & \\
Iowa State: Remote Diagnostic Initiative & www.ent.iastate.edu/rdi/ \\
Western Kentucky: Digital Imaging and & www.ca.uky.edu/agcollege/plantpathology/ \\
Microscope Information by the Extension & PPAExten/digiimag.htm \\
Plant Pathology Group & \\
University of Wisconsin: Distance Diagnosis & cf.uwex.edu/ces/ag/distdiag \\
\hline
\end{tabular}

\section{Equipment}

Computer equipment is changing rapidly, but the basic functions of DAD remain the same. The sequence is simple: (i) acquire the image; (ii) send the image; (iii) view the image (Fig. 2). Images can be acquired using digital cameras or video cameras equipped with a video capture device. Prints and slides can be digitized using slide or flatbed scanners. Plant material (e.g., leaves, flowers, small seeds) can also be scanned directly on a flatbed scanner, which yields the actual size of the specimen in addition to a high-quality image. Digital or video cameras also can be attached to microscopes (Fig. 1) to capture microscopic features of pathogens or host tissue. Live video feed over long distances is also possible using a variety of consumer-oriented or professional equipment that is adaptable to all the functions of still cameras (i.e., through use of a video capture board) and can accommodate multiple sites. Specifications and costs for equipment used by several universities to perform DAD can be found on their websites (Table 2).

Digital images can be posted to a website and viewed by the diagnostician, or they can be sent as e-mail attachments or live video, depending on the needs and capabilities of the parties involved (Fig. 2). Whether images are posted to a website or sent as e-mail attachments depends on how often the service is used and how many individuals will be viewing the images over a period of time. Single or infrequent use of DAD usually employs the e-mail attachment method; those who regularly use DAD find that posting images to a website is more efficient. A dynamic similar to live video is achieved using a combination of e-mail attachments (or web postings) during a telephone conversation. Wireless technology can be used for the same function but is currently slower and more prone to technical difficulty than hard-wired connections

\section{Advantages/Benefits}

DAD offers tremendous advantages when speed and distance are significant obstacles. Poor specimens are not only the result of collecting the wrong plant part, but also of sample degradation in transit. Even with the availability of overnight shipping, samples often arrive too deteriorated for any meaningful diagnosis. This is especially true during hot summer months and long weekends, during which samples are exposed to high heat over extended periods. It is also true for certain samples regardless of ambient temperatures (e.g., rapidly progressing fungal and bacterial soft rots). As for samples originating overseas, a photograph may provide the only means of showing what the sample looked like at the time of collection. Certain diseases are nearly impossible to ship in good condition but are easily recognized in the field (Fig. 3F). 


\section{STILL IMAGE}

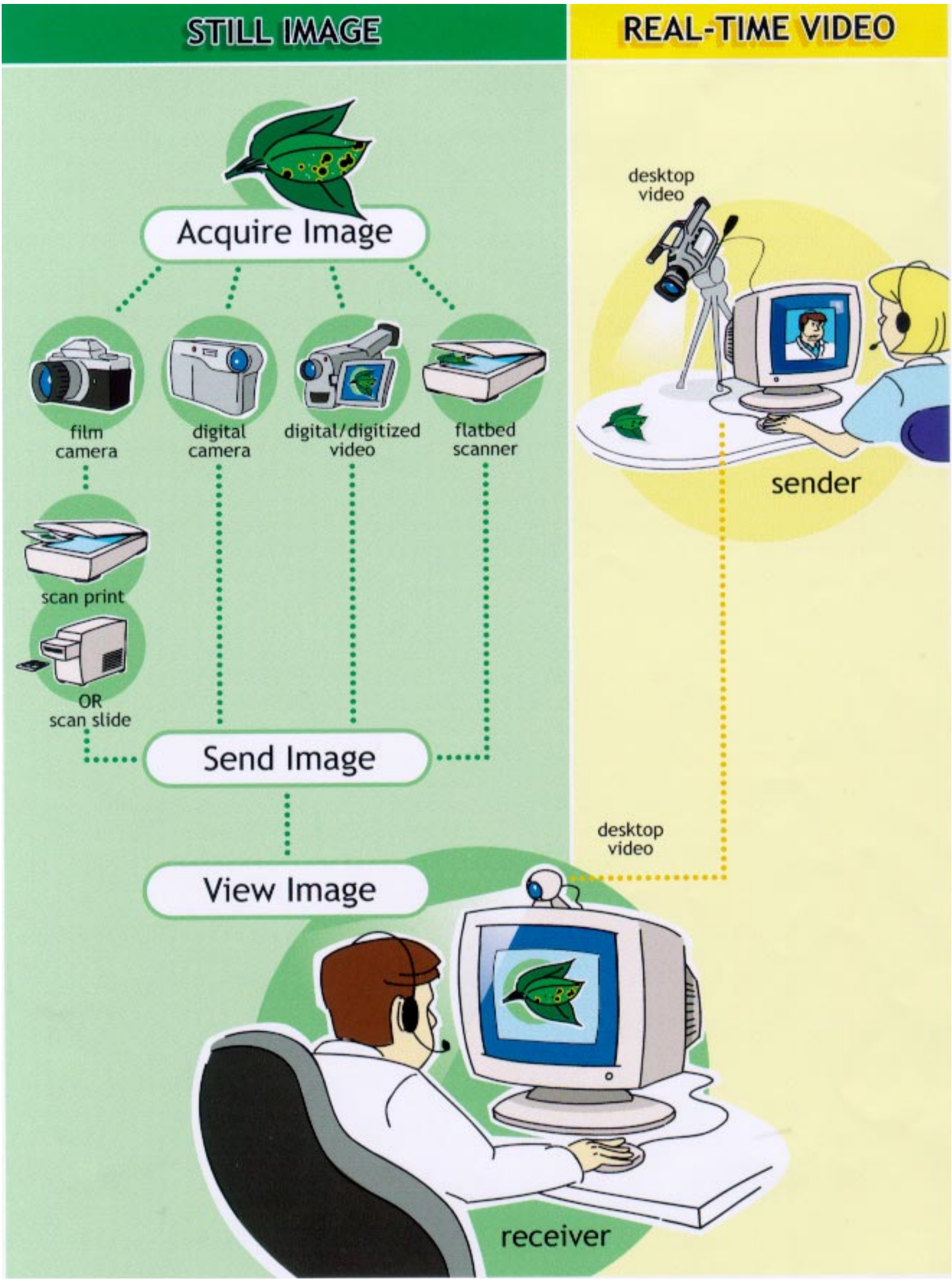

\section{REAL-TIME VIDEO}

ideo 
Digital images do not deteriorate, and their time in transit is negligible. Thus, speed is a major advantage of DAD if images are viewed in a timely fashion. In a best-case scenario (i.e., disease with unique symptoms [Fig. 3A to E], adequate background information, high-quality image, available diagnostician with extensive experience and good judgment), an accurate diagnosis is possible within minutes of taking the image(s). Overnight courier service is not only slower, but more costly (assuming that DAD equipment has been purchased). Additionally, the irrelevance of location is beneficial to both the sender and the diagnostician. It is possible for each of them to send and receive images from virtually anywhere in the world, including grower fields (using cellular modems).

DAD can be a powerful educational tool. Digital image transfer can be used as a preliminary check before live samples are shipped. Images can help a diagnostician determine if a sample is necessary, which plant part should be submitted, and how it should be packaged. In the course of such a conversation, the submitter can gain a better understanding of plant pathology and the diagnostic procedure. Over time, the submitter becomes more adept at problem solving and uses plant pathologists as resources rather than as crutches. In web-based image submissions, the sender can be denied sample submission unless necessary background information has been given. This not only improves
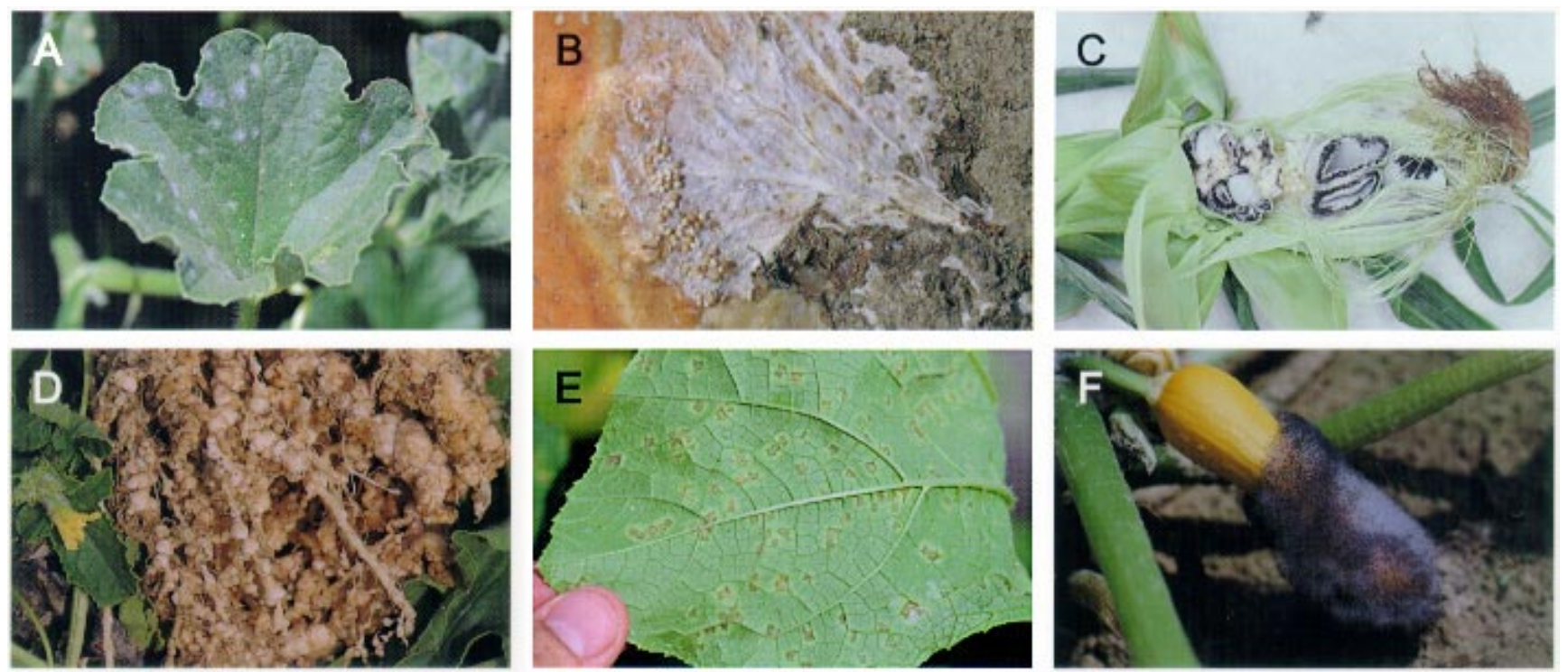

Fig. 3. Examples of signature diseases with characteristic symptoms and signs, well suited for digitally assisted diagnosis (DAD): powdery mildew of cantaloupe caused by Sphaerotheca fuliginea (A), southern blight of pumpkin fruit caused by Sclerotium rolfsii (B), corn smut caused by Ustilago maydis (C), root knot of muskmelon caused by Meloidogyne spp. (D), downy mildew of pumpkin caused by Pseudoperonospora cubensis (E), Choanephora fruit rot of squash caused by Choanephora cucurbitarum (F). (courtesy G. J. Holmes)

Table 3. Plant disease specimens and their suitability for digitally assisted diagnosis (DAD)

\section{Well suited}

Poorly suited

Diseases that produce characteristic diagnostic symptoms and/or signs (e.g., many foliar diseases and postharvest diseases)

Specimens that do not ship well (e.g., plant tissue that wilts and/or rots quickly; depends on conditions during transit)

Diseases that produce ephemeral symptoms and/or signs (e.g.,

Choanephora fruit rot of squash, see Figure 3F)

Specimens that are too large to ship (e.g., trees)

When distance makes it impractical for a field visit

When shipment is too costly, inconvenient, or impossible given existing time constraints (e.g., sample is collected late Friday afternoon on a 3day weekend)

When phytosanitary issues prevent rapid shipment of live samples (e.g., samples of international origin)

When only one pathogen is known to cause the specific symptom on the specific host in a specific location at a specific time of year

When 95 to $99 \%$ confidence in the diagnosis is sufficient When a live sample will not provide additional information

When a diagnosis is needed, but no recommendations are required When you have an excellent cooperator on the other end
Diseases that produce subtle symptoms and/or signs

Most soilborne diseases (exceptions: root-knot nematode, club root)

Involvement of certain soil-related toxic substances (e.g., high soluble salts)

Many turfgrass diseases

When odors or flavors are important for diagnosis

When absolute certainty is required (e.g., regulatory work, research project)

When identification of the pathogen species is required (e.g., which mosaic virus or fungal species when more than one can cause the symptom observed)

Cases in which a visit to the field would reveal other complicating factors (conditions in surrounding areas; images of surrounding areas could be sent, but this depends on the diagnostic skills of the sender) When poor-quality images are submitted

Image shows wrong plant part (e.g., images of leaves are submitted when the diagnostic symptoms are on stems, roots, etc.)

When there are multiple causal agents/mixed infections

When a course of action will be prescribed (e.g., fungicide application) (unless cooperator has information on disease incidence and severity, crop phenology, etc.) 
sample quality, but educates the sender on what information should be gathered during sample collection. This is also an advantage of web-based DAD systems over e-mail attachments.

Images can be sent to many people with a single keystroke. Diagnosticians can quickly get feedback from colleagues with greater experience on specific crops or pathogens, including colleagues from different institutions. Indeed, communication between experienced diagnosticians aided by digital images may represent the ideal scenario for DAD. Digital image transfer is also valuable to researchers, who frequently need to share important photographic information over long distances without the delays of surface mail.

The number of diseases that can be diagnosed from images alone is debatable. Key to the debate is the diagnostic expertise of those sending as well as receiving images. Images taken by someone with training in plant pathology (and good photography skills) will likely illustrate the important aspects of a disease. Diseases that have characteristic symptoms and signs and few if any look-alikes are prime candidates for DAD (Table 3; Fig. 3). If images of the microscopic features of symptoms and signs are included (Fig. 4), many more candidates are added to the list.

For other diseases, images can provide valuable information that otherwise may not be possible. For example, when an onsite visit is not possible, digital images can capture many important features of the specimen as well as the area where the sample was collected. Images can reveal the level of disease severity and the patterns of distribution at the collection site as well as physical structures and symptoms on plant material in surrounding areas. Close-up images of symptomatic plant parts can also be included to provide immediate, valuable diagnostic information before the actual live sample arrives at the clinic.

Industry. Pioneer Hi-Bred estimates savings of approximately one million dollars annually by using their DAD system to diagnose diseases (primarily of corn). The savings arise from less travel to investigate diseases, less time spent on individual diagnoses, less time dealing with disease problems and diagnostics, and improved decision-making based on frequent input by pathologists. Pioneer also claims that diagnoses are achieved with greater speed and accuracy. Problems sending samples overseas and dealing with phytosanitary issues, once huge obstacles, do not exist. Images are archived automatically and are searchable immediately on an expanding database of more than 15,000 images (as of May 2000).

Because Pioneer tests new breeding lines, it wants to find out how these lines react to diseases and other stresses whose symptoms often mimic those of diseases.
Each new breeding line may react differently to disease and abiotic stresses; however, an automated, searchable database allows the company to make rapid assessments from many sites around the world and immediately make that information available to its staff.

The advantages of DAD for Griffin L.L.C. have been in evaluating crop loss in research and evaluation plots with greater speed and less travel, resulting in savings of time and money. In the first year of implementation, more than $\$ 150,000$ was saved in transportation costs when images were used in field evaluations. Another benefit Griffin recognizes is utilization of resources of other companies and instituGriffin can request outside assistance, regardless of its location (J. Bone, personal communication).

\section{Case Study 1: Squash Disease Controlled}

Three months after the distribution of the first agricultural diagnostic imaging stations in Georgia, a sample of a problem tions. When an unfamiliar problem occurs,

in a squash field was submitted. The images were taken by the county extension agent using a handheld digital camera, as well as with video cameras mounted on dissecting and compound microscopes. These images were submitted with crop production information and automatically directed to the extension plant pathologist responsible for vegetables (Fig. 4). He reviewed the images of the symptoms and fungal spores and was able to identify the causal agent, Phytophthora capsici. The disease was diagnosed almost as soon as the images were submitted. Because of the speed of this diagnosis, the grower was able to treat a destructive and rapidly progressing disease before it was too late for control. The result was prevention of disease spread and an acceptable crop yield.

\section{Case Study 2: New Pumpkin Disease}

In September 1999, a county extension agent submitted images of diseased pumpkins from a farm in Terrell County, GA (Fig. 5). The images were viewed by the extension vegetable pathologist in Tifton,
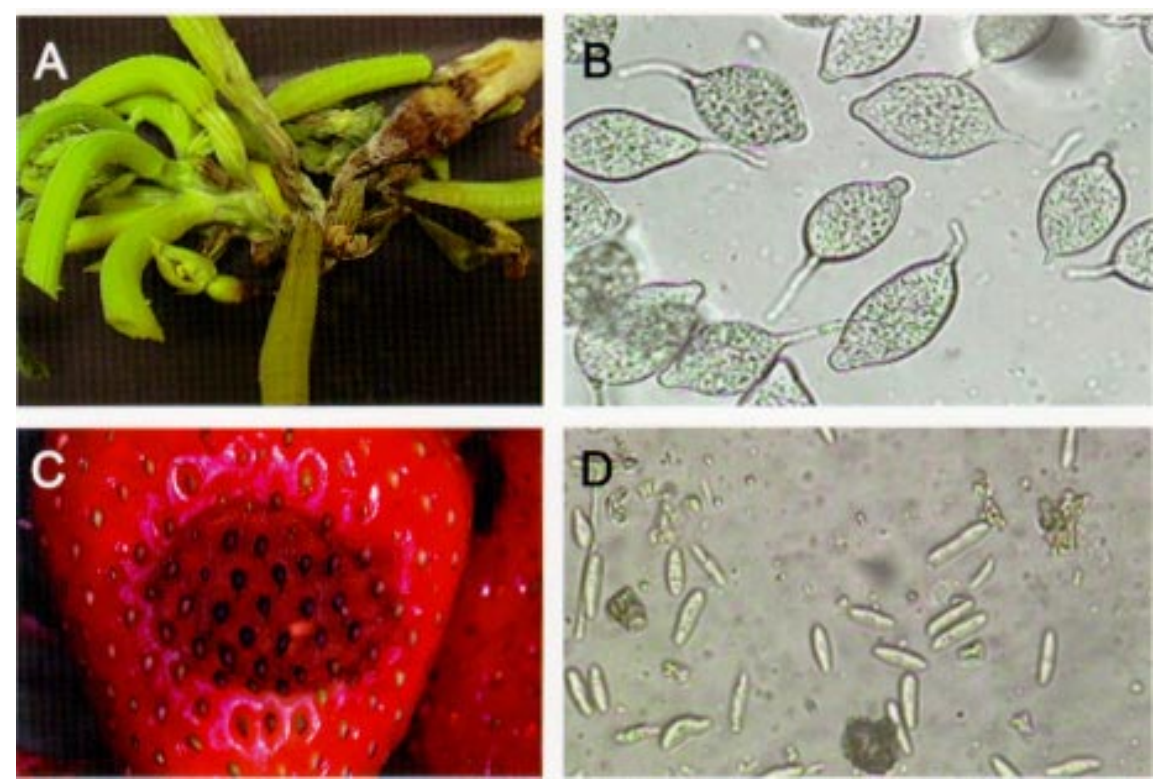

Fig 4. Digital images of diseased squash (A) and sporangia of its causal agent Phytophthora capsici (B); diseased strawberry fruit (C) and its causal agent Colletotrichum acutatum (D). (courtesy University of Georgia)
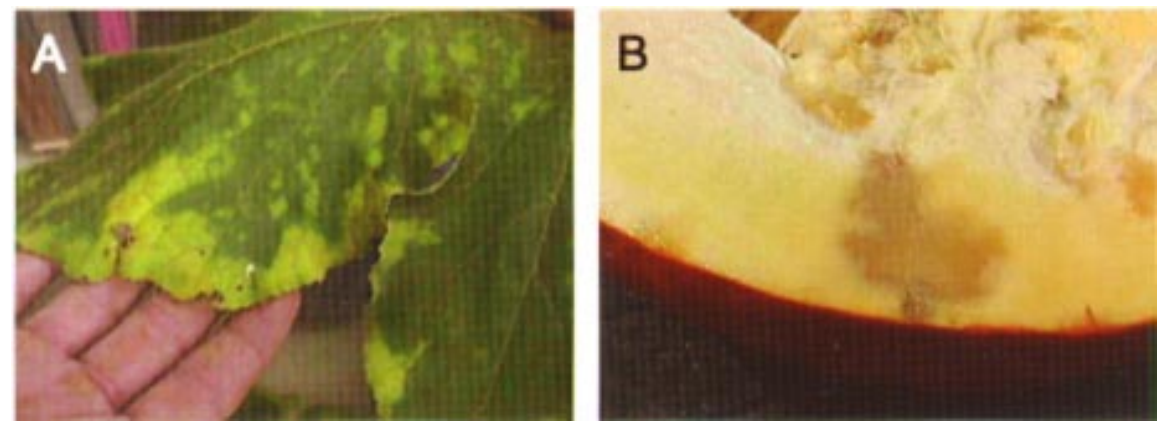

Fig. 5. Digital images of foliar symptoms (A) and symptoms of fruit cross section (B) of Acidovorax avenae subsp. citrulli on pumpkin. (courtesy University of Georgia) 
and an immediate field visit was planned because the symptoms did not match those of any known pumpkin disease. Samples collected from the commercial pumpkin field were found to contain the watermelon fruit blotch pathogen Acidovorax avenae subsp. citrulli. This was the first report of this disease on pumpkin. The images allowed the extension specialist to make an informed decision about the necessity of an on-site visit.

\section{Case Study 3: Overseas Postharvest Disease}

A North Carolina sweetpotato packer shipped a container of sweetpotatoes to Felixtowe, England. When the shipment was inspected in England, a high level of decay was found. Digital images of the rotted roots were taken the same day and emailed to a vegetable extension specialist at North Carolina State University. The images showed classic symptoms and signs associated with Rhizopus soft rot (Fig. 6). Because of the value of the product and insurance coverage, verification with a live sample was requested by the produce broker. The sample was sent by air freight to the United States but was detained by customs officials. After 5 days, the sample Clinic at North Carolina State University and had deteriorated beyond recognition. The sample was so deteriorated that under normal conditions it may have been given the diagnosis of "inadequate sample." However, because digital images were previously viewed, the rotted tissue was examined for characteristic coenocytic presence of the characteristic hyphae coupled with the previously submitted digital images produced a diagnosis with a much higher level of confidence than was possible with only the deteriorated "live" sample. arrived at the Plant Disease and Insect hyphae found in Rhizopus stolonifer. The

\section{One County Agent's Experience}

Extension Agent Tom Dyson in Chowan County, NC, started experimenting with DAD in 1995. His experimentation grew out of what he viewed as a necessity to serve his clientele better. Travel time from the Chowan county seat (Edenton) to the Plant Disease and Insect Clinic at North Carolina State University is approximately $3 \mathrm{~h}$. Dyson frequently found himself in situations in which he needed rapid assistance diagnosing plant problems. Mailing samples took too long, and making the drive to campus was not the wisest use of his time, so he began to investigate digital images to speed up the process.

Dyson started with an older model VHS video camera. Using an inexpensive video capture device (Snappy), he began to send the clinic images of plant problems as email attachments. He quickly realized he was severely limited without a microscope. After seeing the success and potential for this technology, Dyson secured a small grant with which he purchased inexpensive compound and dissecting microscopes, a video camera that attached to the microscopes, a field video camera, and a new personal computer for $\$ 4,000$. At first, images were sent as e-mail attachments, but soon Dyson found that posting the images to a website was more efficient. The images were organized by case numbers and accompanied by a voice message describing the nature of the problem. He would alert the diagnostician about the digital sample via e-mail, which contained a link to the website.

With each sample, Dyson learned more plant pathology. Before sending a live sample, he would attempt a diagnosis with a set of images. This resulted in a confident diagnosis for approximately $95 \%$ of the digital specimens. Reasons for this high degree of success included the com-

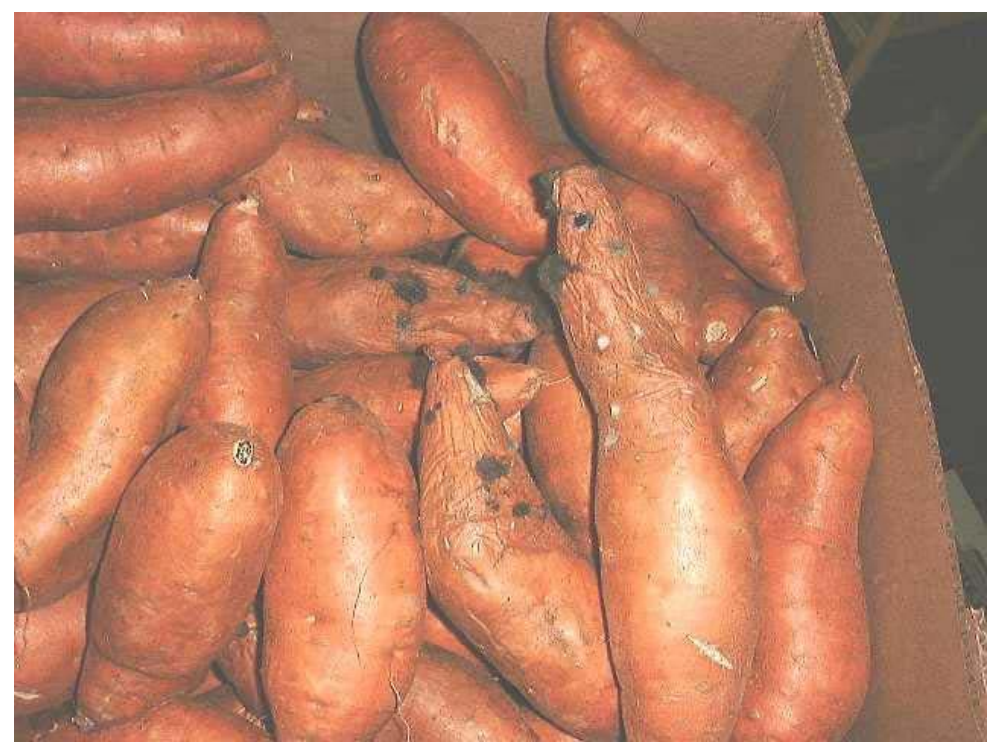

Fig 6. Digital image of sweetpotato shipment to England documenting a decay problem due to Rhizopus stolonifer. (courtesy Exotic Produce, Ltd.) pleteness of the image set, accompanying information, and Dyson's efforts to use the technology only when it was most appropriate for the situation.

Recently, Dyson set up real-time video conferencing (Fig. 2) with campus-based extension pathologists using inexpensive, consumer-oriented equipment, which uses a standard analog telephone line. The disadvantage of video conferencing is lower resolution images (high resolution is possible but at the expense of speed) and the need to have both parties present. The advantage is a "guided" diagnostic procedure, generally resulting in a more reliable diagnosis and greater potential for learning and teaching. It should be noted that while such interactions are excellent teaching moments, they can be time-consuming. However, it's hard to imagine a more time-consuming diagnostic technique than the onsite visit. For a short article and links to Dyson's system, go to http://www.ces. ncsu.edu/depts/agcomm/writing/dyson.htm.

\section{Disadvantages/Risks}

DAD and telemedicine share some of the same risks: liability concerns, absence of minimal standards, and resistance to new technology. In contrast to telemedicine, reimbursement and licensing issues across state lines are negligible for DAD. Additional concerns include increased workload for diagnosticians, inherent weaknesses of the technology, and poor photography.

Some diagnosticians argue that few, if any, diseases can be diagnosed even from the best image with enough reliability to be legally binding. Many diseases produce general symptoms. For example, root problems produce aboveground symptoms (wilt, chlorosis, stunting, etc.) that can be caused by many different pathogens and abiotic diseases. Even with leaf spots, two different pathogens can produce strikingly similar symptoms that differ in ways that are subtle and difficult to detect. Images often will not contain sufficient detail to assist in diagnosis, constituting a waste of time and possibly misleading the diagnostician into making an incorrect diagnosis. Certain types of information cannot be conveyed with images. For example, how does one determine $\mathrm{pH}$ and soluble salts from an image? They must be measured from a soil sample.

How would a diagnosis based solely-or largely — on a digital image hold up in a court of law when thousands of dollars may be at stake? For this, there is no precedent in telemedicine or DAD. Every diagnosis would have to be handled individually, and the merits of digital images would depend on the disease, the quality of the images, and the soundness of the diagnostician's interpretation. The establishment of minimum standards might be helpful in such cases, but this need predates DAD. 
Although a great advantage, lack of sample degradation in digital images could also have negative effects. Diagnosticians may choose to diagnose digital samples last, since they will not decompose like the samples in the cooler. This would defeat the advantage of speed.

Some users of DAD complain that taking images is time-consuming and generally does not lead to a diagnosis without an accompanying live sample. In fact, some clinics have adopted the policy of not making a diagnosis from images alone. Thus, submitters may view the taking of digital images as an additional procedure that is unnecessary and wasteful.

Additionally, diagnosticians, who are often overwhelmed by their current workloads, may see DAD as an unwelcome addition. Because digital image transfer is so easy, clinics could become inundated with digital images from an ever-increasing number of clients. In addition, clients could send the same image(s) to multiple clinics. Because state and national boundaries are irrelevant in telecommunications, are we opening ourselves up to a flood of samples from other states and countries in which such services are scarce? As with the increase of homeowner questions via the introduction of university and clinic websites, will clinic workloads increase exponentially with submission of digital images only a keystroke away? Some university clinics restrict image submission to county extension personnel. This reinforces county delivery and in-service education, and helps ensure quality images.

A picture may be worth a thousand words, but as one pathologist noted, "10 minutes in the field is worth 10,000 pictures." Accurate disease diagnosis is challenging, even when using live specimens and on-site visits. Should we embrace a technology that reduces the entire disease signature to a photograph or two? Can we substitute the on-site visit and subsequent examination of plant material in the laboratory for a few images? The key to answering these questions lies in the skills possessed by the parties involved. Diag- nosticians often make significant observations simply because they hold the specimens in their hands.

Inadequate, nonrepresentative specimens have always been a problem. Now, the same person that submitted a poor live specimen will likely submit a digital image of a poor specimen. With DAD, poor skills in photography offer yet another means of producing poor-quality samples. Photographing the important diagnostic features of a plant disease is not easy. One should be both a good pathologist and a good photographer. A diagnosis can only be as accurate as the information provided. Therefore, poor images constitute incomplete information that could lead to inaccurate diagnoses.

Over time, plant pathologists have gone to the field less and less. DAD may be one more excuse to sit in an office and stare at a computer screen. This jeopardizes what we know as the art and science of plant disease diagnosis and may lead to a loss in diagnostic competence. County agents, extension specialists, and consultants need to visit sites, interact with their clientele, look at live plant material, and become acquainted with the complexity of a disease situation firsthand.

Although the equipment used in DAD is becoming more affordable, the initial expense can still be significant. A person starting from scratch would have to procure a computer, camera equipment, and Internet access at the bare minimum. Learning how to use this equipment is at best time-consuming and at worst extremely frustrating. Many people choose not to use computers for these reasons.

Finally, it is conceivable that legislators and administrators would see DAD as a means of doing more with less. This could lead to a reduction in the number of diagnosticians and clinics.

\section{Case Study 4: \\ Wilted Tomato}

A grower was concerned about yellowing and wilted tomatoes from his 20-acre field in Georgia. Although this sample consisted of three images, none of them provided more detail than is seen in Figure 7A. The wilting and chlorosis could have been caused by a variety of biotic and abiotic agents acting singly or in combination. The county agent was instructed to submit a live sample to the clinic and be sure to include soil and roots. Another course of action would be to work with the county agent by taking him/her through a diagnostic process to confirm or deny the presence of various suspected diseases. This approach would be more time-consuming but more educational.

\section{Case Study 5: Dead Patches of St. Augustinegrass}

A homeowner was concerned about dying patches on St. Augustinegrass (Fig. 7B). Five images were submitted to Georgia's DDDI system: three similar to the one in Figure 7B and two close-ups of individual stolons and roots. Although the images are descriptive, no diagnosis could be rendered based on the images provided. Many turfgrass diseases are difficult to identify and may involve mixed infections. The homeowner was instructed to send in a live sample and given specific directions on where and how to collect and ship the specimen.

\section{Case Study 6: Oak Tree Problem}

A homeowner in Indiana wanted to know why his oak tree was sparsely foliated. The image in Figure 7C was the only information provided. Clearly, no diagnosis is possible from this image. The homeowner was asked to send additional images, including close-ups of the symptoms and signs in question and a description of the problem. Follow-up images submitted to the clinic were diagnostic for oak tatters, a problem observed throughout the midwestern United States (10).

\section{Real-World Approach}

The time, energy, and resources that a diagnostician spends on a sample are often proportional to the level of reliability or
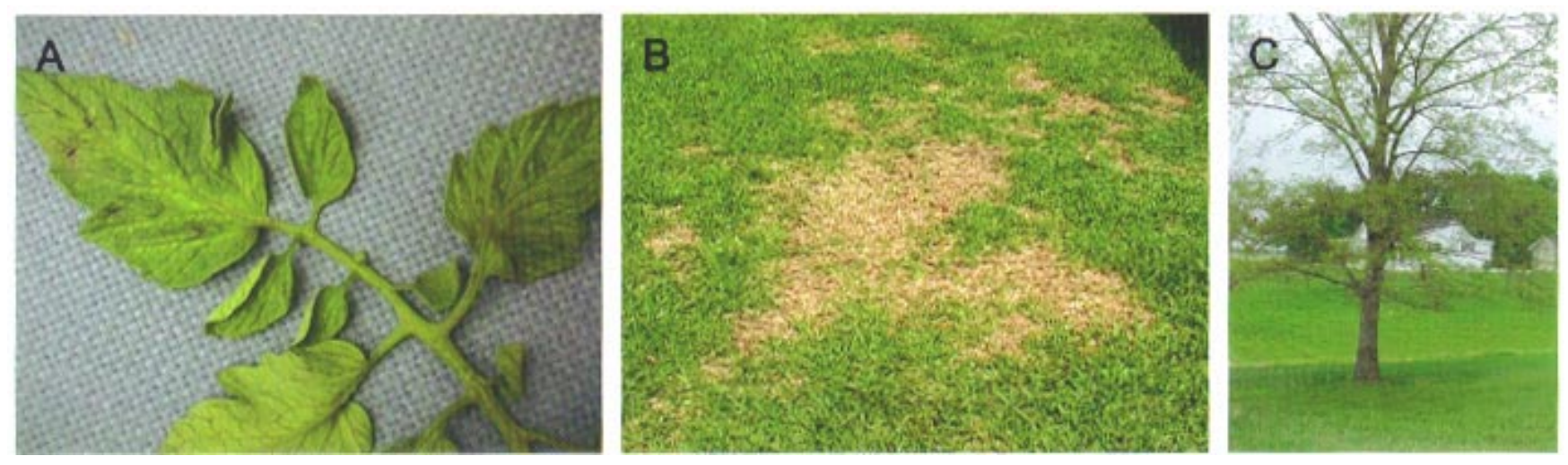

Fig. 7. Examples of images that do not provide sufficient information for a confident diagnosis: chlorosis and mild wilting of tomato (too general) (A); dead spot in St. Augustinegrass lawn in home landscape (too general) (B); oak tree with foliar problem (need close-up of leaves) (C). (courtesy Purdue University) 
confidence desired in the final diagnosis. For example, the input of a diagnostician involved with samples of a regulatory nature is consistently high because of the high level of confidence required for each diagnosis. In contrast, the input and level of confidence required of a diagnostician working on an inadequate homeowner sample would be much less. This may sound biased and unscientific, but it should ring true to veteran diagnosticians. The reality of diagnosing many samples on a daily basis makes this necessary. To treat each sample as if a $100 \%$ reliable diagnosis is necessary is not productive use of a diagnostician's time. Thus, when diagnosing plant diseases, the diagnostician must seek a proper balance between competing objectives of speed, accuracy, cost, importance of the course of action, and the difficulty in arriving at a diagnosis.

Shurtleff and Averre (19) described five levels of confidence used in making diagnoses. All five levels are more than $85 \%$ reliable: a $100 \%$ reliable diagnosis requires the fulfillment of Koch's postulates; a 99\% reliable diagnosis is the goal of diagnosticians; a 95 to $99 \%$ reliable diagnosis is the level at which most good diagnosticians operate (growers and courts of law normally accept); and an 85 to $95 \%$ reliable diagnosis is possible when available information is incomplete but consistent with the causal agent. (The grower must assess the merits and act accordingly.) A fifth level of confidence is called "exclusion." The exact cause of the problem cannot be determined, but specific diseases are eliminated with $100 \%$ reliability because critical components of the disease signature are lacking. Anything below 85\% reliability should be considered a "suspected cause" rather than a "diagnosis." While seldom stated, all diagnoses have a level of confidence associated with them. This is the appropriate context in which to consider the merits of DAD.

\section{Challenges and Opportunities}

DAD provides significant challenges and opportunities. In the final analysis, most of the challenges are not directly related to the central question of using digital images for disease diagnosis. Poor photography, clinic workload, time commitment, equipment costs, and reluctance to use new technology are all separate issues that can be overcome. The main questions are, should DAD be used, and if so, how? If digital images are viewed as a tool rather than a substitute for existing methods, the risks of DAD are perhaps no greater than they are when using conventional diagnostic methods. Meanwhile, the benefits of DAD are significant in overcoming the problems of speed and distance that have plagued clinics.

The degree to which DAD is accepted or rejected is bound to be influenced by one's line of work. For isolated agriculturists (e.g., county agents, crops consultants, industry with international operations, etc.) called upon to make diagnoses on a frequent basis, DAD is likely to be welcomed because it will facilitate communication. The more isolated the agriculturist, the more desirable is DAD. For the clinic diagnostician who may already be suffering from a heavy workload, DAD might be avoided, because it could be perceived as generating an increase in samples of poor quality and require a new or modified handling system. However, at the writing of this paper, institutions using DAD have not experienced noticeable increases in their workload (G. Ruhl, unpublished data). Clientele can be educated to understand that DAD is not the path of least resistance. DAD requires submission of good digital images. Submitters should quickly realize that poor or nonrepresentative images are a waste of everyone's time.

DAD may be especially attractive to developing countries where the local expertise could be supplemented by specialists from all over the world. Consider the isolated plant pathologist who encounters new crops and diseases that may be characteristic to one familiar with the crop, but would require significant personal input to arrive at a confident diagnosis. Digital images would be a welcome additional tool. DAD may also become more important as resources continue to shrink and if disease clinics become regional centers. In such a scenario, the clinic could rely on diagnosticians at remote sites.

Consider the traditional "live" sample. A high proportion of these samples provide insufficient information from which to make a diagnosis. Interestingly, while diagnosticians are well aware of this problem, it has received little attention in the literature (8). Does this fact make mailed, live samples useless? Does the use of mailed samples replace the on-site visit? The answer to the question at both extremes is no. As with any tool, danger lies in over-reliance and unrealistic expectations.

Despite the expectation for widespread use of molecular techniques (14) in clinics, they are seldom used. Visual inspection (including microscopic features) is still the most important aspect of most diagnoses. Two of the most useful tools, the microscope and the moist chamber, have been around since our discipline began. Now we have a new tool that can enhance these essential visual tools. None of the recent reviews $(6,8,9,15)$ predicted this new tool for disease diagnosis. All eyes have been fixed on molecular techniques, waiting for them to become robust and inexpensive assays. Meanwhile, the use of digital images for DAD appeared, giving speed to symptom recognition and offering improved background information about diseased plants and their environments. This technology is readily available to diagnos- ticians worldwide. Do we realize the impact that this will have on diagnostics? Few technologies have gained such widespread use in such a short period of time.

Will DAD dramatically increase sample volume for disease clinics? While boundaries may erode, there are other checks and balances to prevent a huge surge in samples. Most clinics operate at capacity for much of the year. Increased samples from out-of-state can be quickly identified and dealt with as needed. Perhaps it will be more difficult to deal with the problem on an individual basis (e.g., by a plant pathologist known for expertise on a specific host).

The process of DAD is currently being tested for accuracy of samples submitted electronically versus the accuracy on a diagnosis made by traditional methods using the same sample. The University of Florida is currently conducting such a study (see URL on Table 2). At Purdue University's Plant and Pest Diagnostic Lab, a pilot project funded by an Extension Distance Education grant will include a blind study of the accuracy of digital versus actual sample diagnosis (Table 1). A study of the cost-effectiveness of DAD is also needed. Other issues to consider include the establishment of standards on what constitutes a reliable diagnosis. Should cameras and monitors used for DAD be required to be at a specified resolution and calibrated for accurate color reproduction? Should any diagnosis made from images alone be deemed "unreliable"? These are not new questions, but the incorporation of DAD into diagnostic procedures encourages us to revisit them.

\section{Conclusions}

We return to the question: what is a picture worth? The answer depends on what information the picture contains and who is examining it. At its simplest, DAD is nothing more than a means of improving communication. This improvement, however, may have a profound impact. It drastically reduces the problems of distance and speed. It allows the expert to view more problems and the novice to seek assistance more quickly and effectively. The potential for client education in the process of DAD is perhaps one of its greatest benefits. Conversely, DAD has many of the same pitfalls as traditional diagnostic methods and some new ones. While there is potential for use and abuse, this discussion has illustrated that accurate diagnosis can be achieved when high-quality digital images are submitted to a skilled diagnostician. Perhaps no other tool has had a more rapid, widespread impact on plant disease diagnostics.

\section{Literature Cited}

1. Benschoter, R. A. 1967. V. Television. Multipurpose television. Ann. New York Acad. Sci. 
142:471-478.

2. Benschoter, R. A., Wittson, C. L., and Ingham, C. G. 1965. Teaching and consultation by television. Mental Hosp. 16:99-100.

3. Briere, S. C., and Franc, G. D. 1998. Use of digital images to aid in disease diagnosis at the University of Wyoming Extension Plant Pathology Lab. Phytopathology 88:S11.

4. Buckner, F. 1998. Telemedicine: The state of the art and current issues. J. Medical Practice Manage. Nov/Dec:145-149.

5. Dyson, T. L. 1999. Digital images for diagnosis: A county agent's perspective. Phytopathol. News 33:183.

6. Fox, R. T. V. 1993. Principles of Diagnostic Techniques in Plant Pathology. CAB International, Wallingford, UK.

7. Grigsby, J. 1995. Current status of domestic telemedicine. J. Medical Syst. 19:19-27.

8. Grogan, R. G. 1981. The science and art of plant-disease diagnosis. Annu. Rev. Phytopathol. 19:333-351.
9. Hansen, M. A., and Wick, R. L. 1993. Plant disease diagnosis: Present status and future prospects. Adv. Plant Pathol. 10:65-126.

10. Haugen, L., Marshall, P., Carlson, J. C., Vitosh, M., and Hayes, E. 2000. Oak tatters. Pest Alert NA-PR-02-00. U.S. Dep. Agric. For. Serv.

11. Holmes, G. J., Creswell, T. C., and Dyson, T. 1998. Digital disease diagnosis in practice. Phytopathology 88:S39.

12. Holmes, G. J. 1999. The ethics of digital diagnostics-A second rebuttal. Phytopathol. News 33:183, 191.

13. Holmes, G. J., Creswell, T. C., and Dyson, T. L. 1999. Rebuttal to "Digital disaster and the ethics of virtual plant pathology"-A response. Phytopathol. News 33:85, 96.

14. Miller, S. A., and Martin, R. R. 1988. Molecular diagnosis of plant disease. Annu. Rev. Phytopathol. 26:409-432.

15. Putnam, M. L. 1995. Evaluation of selected methods of plant disease diagnosis. Crop
Prot. 14:517-525.

16. Ribeiro, O. K. 1999. Debate on digital images for diagnoses. Phytopathol. News 33:134.

17. Sherwood, J. L. 1999. Rebuttal to "Digital disaster and the ethics of virtual plant pathology" "And now for the rest of the story..." Phytopathol. News 33:85.

18. Sherwood, J. L. 1999. What time is it? It's tool time! Phytopathol. News 33:161.

19. Shurtleff, M. C., and Averre, C. W. 1997. The plant disease clinic and field diagnosis of abiotic diseases. American Phytopathological Society, St. Paul, MN.

20. Stowell, L. 1999. The ethics of digital diagnostics-A call for APS leadership. Phytopathol. News 33:116.

21. Stowell, L. 1999. Digital disaster and the ethics of virtual plant pathology. Phytopathol. News 33:62.

22. Thrall, J. H., and Boland, G. 1998. Telemedicine in practice. Seminars Nuclear Medicine 28:145-157.

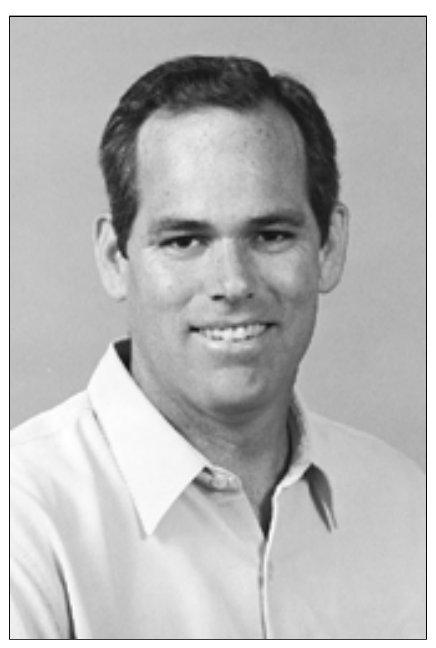

Gerald J. Holmes

Dr. Holmes is assistant professor and cooperative extension specialist at North Carolina State University in Raleigh. He received his B.S. degree in agronomy in 1987 from the California State Polytechnic Institute at Pomona and his Ph.D. in plant pathology from the University of California at Riverside in 1994. After spending 3 years as a plant pathology farm advisor in Imperial County, CA, Dr. Holmes joined the Department of Plant Pathology at North Carolina State University in 1997, where he has had responsibility for extension, teaching, and research on vegetable crops, with emphasis on cucurbits and sweetpotatoes. Dr. Holmes teaches a graduate-level course (Plant Disease: Principles, Diagnosis, and Management) designed for county extension agents, industry, and nonplant pathology majors. The course is taught via live, interactive video between Raleigh, Plymouth, and Fletcher, NC. His research focus is on the etiology, epidemiology, and management of vegetable diseases, including postharvest diseases of sweetpotato.
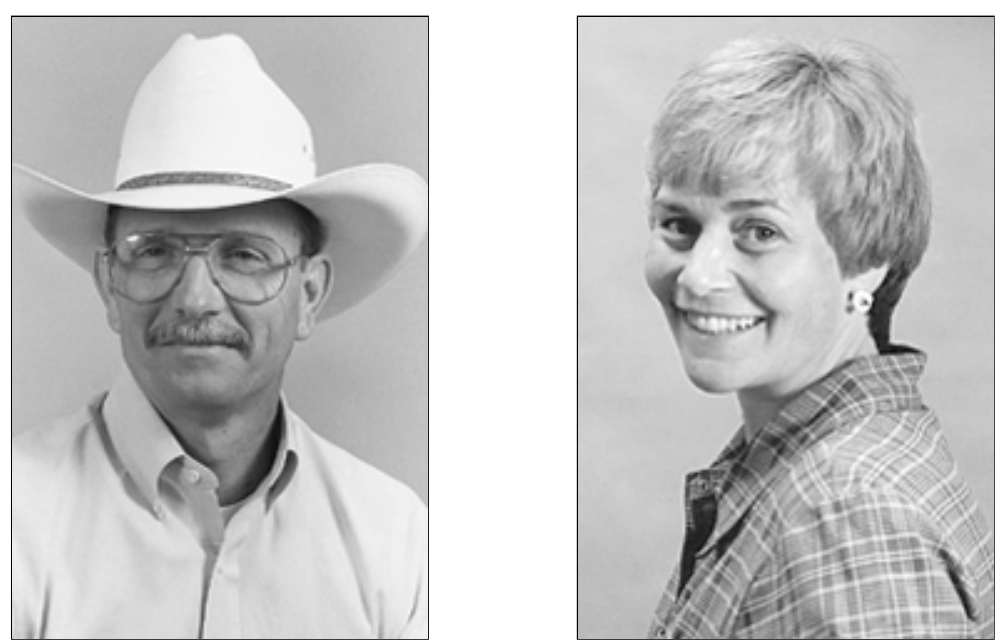

Edward A. Brown

Gail Ruhl

Dr. Brown is professor and statewide coordinator of extension programs in plant pathology at the University of Georgia. He received his B.S., M.S., and Ph.D. degrees in plant pathology from the University of Georgia. His major extension education responsibilities include turf, forage, and forestry diseases, and he also teaches forest pathology. His interest in diagnostics was initiated in 1975 when he was diagnostician in Georgia's first formal Plant Disease Clinic. Dr. Brown is the co-principal investigator in Georgia's successful Distance Diagnostics through Digital Imaging Project.
Ms. Ruhl is the senior plant disease diagnostician for the Plant and Pest Diagnostic Lab (P\&PDL) at Purdue University, West Lafayette, IN. She received her B.S. from Cornell University and her M.S. in plant pathology from Purdue. Her interest in diagnostics during her graduate school years was rewarded with her appointment in 1979 as the sole diagnostician and director of Purdue's first formal Plant Disease and Weed Identification Clinic. Following the creation of an integrated diagnostic lab (P\&PDL) in 1990 and the hiring of an administrative director, her primary responsibility has been the diagnosis of plant problems for all commodity groups, including the rendering of control recommendations. She conducts the disease diagnostics portion in Master Gardener, Certified Crop Advisors, and Commercial Pesticide Applicator training programs, develops and presents youth education programs on plant pathology topics, and participates in various field days and workshops. Gail has been an active participant on the APS Diagnostics Committee, past editor and current managing editor of the Diagnostic's Committee official newsletter, Plant Diagnostics Quarterly (PDQ), and chair of the APS Diagnostics Working Group for the past 3 years. 